or two points on which they seem to have misunderstood me. As one of the examiners who set the question challenged by Mr. $\mathrm{H} \epsilon$ ath, I defended it, and pointed out that it bore a very close relation to medical science, besides showing, by the simplicity of the solution, that it was one of the mildest questions which could be set.

If my friend Dr. Beale will refer to my former letter, he will see that I nowhere regard the production and waste of heat in the body as one of the mildest of questions.

I ask whether a medical student should not know something of such important matters, and wish to imply that, in order to know, he must acquire some knowledge of the simplest principles of heat. $\mathrm{He}$ is not likely to acquire these unless they form a part of the preliminary training of medicai students. I presume Dr. Beale will admit that just so far as man can be regarded as a molecular body, capable of absorbing or radiating heat, to the same extent must the laws of molecules apply to him; for his position is untenable that medical men need a knowledge of Physics, if the laws of Physics do not apply. His remarks on materialism are not warranted by anything in my letter, and do not apply to me. I will not attempt to answer in these pages the general questions proposed by Dr. Beale, on the heat-giving properties of food, or on the waste of heat from the body, nor to describe the methods by which researches on them have been or may be carried out. It is well known, and a medical man who wishes to be stamped with a medical degree ought to know, how much heat a given quantity of food is capable of producing, and also that this amount of heat is exactly equivalent to a certain definite amount of energy : the form in which this energy will show itself in the human body in all the different stages of growth and decay, both in health and disease, is essentially a question for medical men to study.

Physical Laboratory, King's College W. G. ADAMS

\section{Diathermacy of Flame}

WILL you be so good as to allow me to draw the attention of your correspondent, Mr. W. Mattieu Williams, to what appears to be an oversight in his letter on "The Diathermacy of Flame," published in your number of Oct. I7 last. Near the bottom of col. I, page 506, he says, "My flames were thus maintained at a constant mean cistance from the thermometer;" and, farther on, "Here, then, is a serious discrepancy. get an increase of $4^{\circ}$ by the first addition of two flames, and by eight such additional pairs obtain an increase of $34^{\circ}$ instead of the $32^{\circ}$ due to theoretical diathermacy," \&c. "The explanation of the discrepancy seems to be that the radiant heat from a flame, like that from any other body, varies as the inverse square of the distance, and therefore the total effect is proportional to $\frac{\mathbf{I}}{d^{2}}+\frac{\mathbf{I}}{d^{\prime 2}}+\frac{\mathbf{I}}{d^{\prime \prime 2}}+\&$ c., not $\frac{\mathbf{I}}{d}+\frac{\mathbf{I}}{d^{\prime}}+\frac{\mathbf{I}}{d^{\prime \prime}}+\&$ c., where $d, d^{\prime \prime}$, \&c., are the distances of the flames from the thermometer ; in which latter case the order of lighting the jets would answer the desired object.

Without going further into the subject, I would also draw attention to the desirability of keeping the gas at constant pressure, in order that the flames may be always of the same size and shape. It does not appear to be sufficient merely to record the quantity of gas consumed.

The Castle, Parsonstown, Nov. 5

Rosse

\section{The Corona Line}

IT is rather absurd, as Capt. Herschel says, for an American to carry on a discussion with a resident of India through a London periodical; but there are one or two points in his letter of July 29th which I should like to notice.

In the first place, let me acknowledge my mistake as to the original proposer of a chart of the spectrum based upon a scale of inverse wave-lengths; the error arose in the manner Capt. $\mathrm{H}$. supposes. Let me add also my profound satisfaction-shared, I am sure, by all who work with the microscope-on learning, few months ago, that such a chart is in preparation, and that under the charge of a committee of the British Association.

Next, as to the question, "What guarantee was there that No. 3I of the Preliminary Catalogue was the 'coronal line,' anterior to the Dodabetta measurements ?"

In 1869 the case stood thus, so far at least as my own observations are concerned:-In July I had found (not discovered, for
Mr. Lockyer had anticipated me, although I did not know it until October) that the 1474 dark line was generally reversed in the spectrum of the chromosphere. I had been led to examine this part of the spectrum with especial care by the report of green lines seen by Pogson and Rayet during the eclipse of 1868 .

On the forenoon of the day of the eclipse of 1869 (August 7) this line was distinctly reversed at several points on the sun's limb, and with my instrument no other bright line could be seen near it. When, therefore, in the afternoon during the eclipse, I saw in that part of the spectrum a strong, solitary bright line, I considered myself warranted in identifying it with my old acquaintance, 1474, particularly as the measurements of Prof. Harkness, with a one-prism instrument, accorded as well as could be expected.

In 1870 the matter was examined more critically. A few minutes before totality, the 1474 line being already distinctly, and even conspicuously, reversed, the cross wires of the spectroscope micrometer were carefully adjusted upon it, and as soon as totality began the corona all around the sun was thoroughly explored without disturbing the micrometer setting. 'The bright line remained entirely unchanged in position under the whole dispersive power of thirteen prisms, very bright near the moon's limb, but fading to imperceptibility at a distance of from $10^{\prime}$ to $20^{\prime}$.

It seems to me, therefore, that the Dodabetta measurements must be regarded as merely confinming what was before fully ascertained. Of couse it was highly desirable that the fact should not be allowed to rest upon the testimony of any one observer.

Then as to another point-the puzzling coincidence between the coronal line and a line in the spectrum of iron.

The absence of hundıeds of other and more important iron lines from the coronal spectrum, and the difficulty of supposing the vapour density of this metal less than that of hydrogen, or of otherwise accounting for its presence in such quantities in the upper portions of the solar atmosphere, made it from the first highly improbable that this line could be due to iron. Now I think I can add another fact pointing in the same direction. During the past summer, observing at an altitude of more than 8 , ooo It., I have repeatedly witnessed solar disturbances by which the b's, the $\mathrm{E}$ lines, and the double iron line $1463 \mathrm{~K}$ (all in the same field with 1474) were considerably displaced and cistorted, while 1474, and some other lines of unknown origin near it, were not in the least affected. I think therefore I may say that 1474 does not usually sympathise with the lines of the iron spectrum, and this adds to the probability that it is of different origin.

But, on the other hand, so close is the coincidence, that the more I examine the matter, the harder it is to suppose that we have to do with a mere accidental juxtaposition. For one $\mathbf{I}$ am very anxious to hear whether the new and unequalled instruments of Dr. Huggins throw any further light upon the subject, and I should be very glad to hear that they show the non-coincidence of the bright and dark I474's, because it would greatly simplify the problems, but I cannot say that I expect such news.

Now if the coincidence is absolute, there must be some reason for it; either the coronal matter exists in terrestrial iron as an impurity, or the two substances have in their molecular constitution some similar dimension, some common parameter, which accounts for this identical vibration-period; for I take it even an absolute coincidence between the lines of two spectra entirely independent in their origin is infinitely impossible-I mean of course coincidence determined to be such by a spectroscope of infinite dispersive power.

As to the numerous coincidences observable upon the charts of Kirchhoff and Angström, between the lines of iron, titanium, and calcium, it seems most likely that they originate in the slight impurity of the metals used by the experimenters. Certainly the matter merits most careful investigation, for if this is not the case a road would seem to be opened by which we may hope ultimately to penetrate many of the secrets of metallic molecules.

Dartmouth College, U.S.A. Oct. Io

C. A. Young

\section{Brilliant Meteors}

ON Sunday evening, (Nov. 3), at '5.30, a magnificent "bolide" was observed" at Glasgow, shooting athwart the sky. It made its first appearance in the Constellation Auriga (about 